\title{
FIELD MEASUREMENT AND NUMERICAL STUDY OF EXTERNAL WIND PRESSURE OF RIBBED COOLING TOWER
}

\author{
Yi-chen Yuan ${ }^{1}$, Zi-hou Yuan ${ }^{2,4^{*}}$, Ming-xiang Chen ${ }^{3^{*}}$
}

1. Huazhong University of Science and Technology, School of Civil and Hydraulic Engineering, Wuhan, Hubei, 430070, China; hustyyc@126.com

2. Wuhan Textile University, Hubei Key Laboratory of Digital Textile Equipment, Wuhan, Hubei, 430073, China; whuyzh@163.com

3. Wuhan University, School of Civil Engineering, Wuhan, Hubei, 430072, China; 2002025@wtu.edu.cn

4. Southeast University, Key Laboratory of Concrete and Pre-stressed Concrete Structure of Ministry of Education, Nanjing , Jiangsu ,211189, China; whuyzh@163.com

ABSTRACT

The hyperbolic thin-shell cooling tower is a typical wind-sensitive structure, and the full-size measurement is the most direct and important way to study the distribution of wind pressure on the surface of the cooling tower. But due to the limitations of engineering conditions and meteorological conditions, the field measured data are relatively lacking, and the field test data of ribbed cooling towers are less. In order to analyze the wind pressure distribution on the surface of the cooling tower, we chose a ribbed cooling tower in Toksun County, Xinjiang, China, where there is strong wind all year round, and field measurements were carried out to understand the wind load characteristics of the tower under the perennial dominant wind direction and the maximum wind direction. It is found that the absolute value of the negative pressure on the leeward side is larger than that in the code and the fluctuating wind pressure coefficient fluctuates greatly when the field measured wind speed is greater than $10 \mathrm{~m} / \mathrm{s}$ (15 meters above the ground). And for circular section cooling tower, the Reynolds number $(\mathrm{Re})$ has great influence on wind pressure. With the increase of $R e$, the absolute value of the average negative pressure of the tail wind pressure coefficient increases, which should be paid attention to in design. Meanwhile, the regression curves of the average wind pressure coefficients measured on site under several typical working conditions are given by using the least square method, and its form is consistent with the standard (but the coefficients are different). Finally, Fluent software is used to calculate the external wind pressure of the cooling tower, and the variation law of numerical calculation is consistent with that of the field measured results, the Chinese code and German code.

\section{KEYWORDS}

Ribbed cooling tower, Wind pressure coefficient, Field measurement, Code, Reynolds number

\section{INTRODUCTION}

Wind load is one of the main loads of hyperbolic cooling towers. In 1965, the cooling tower group of Ferrybridge power station in England collapsed when the average wind speed was only 
$19 \mathrm{~m} / \mathrm{s}$. And the cooling tower at Scotland's Ardeer power plant collapsed under strong winds in 1973[1].

These accidents have attracted the attention of the International Wind Engineering Society and experts at home and abroad. Experts have measured the wind pressure distribution characteristics on the cooling tower surface ${ }^{[2]}$, wind tunnel test flow characteristics compensation [3,4], effect of group tower and adjacent landform on wind pressure distribution on the surface of tower [5], buckling stability and ultimate bearing capacity of tower cylinder under wind load [6,7], and fluctuating wind pressure causes random dynamic response of ventilator shell [8].

The hyperbolic circular section cooling tower is a typical streamlined wind-sensitive threedimensional thin-walled space structure, and the wind pressure distribution on the surface is significantly affected by Re. Re of actual cooling tower is about $1 \times 10^{7} \sim 1 \times 10^{8}$. However, Re of the structural model and the prototype differs by $2 \sim 3$ orders of magnitude. At present, it is impossible to simulate the flow pattern of the cooling tower structure under such high Re by increasing the test wind speed or the scale ratio of the model. Although some scholars have tried to change the surface roughness of cooling tower to simulate the high Re effect of large scale ratio model about surface circulation ${ }^{[9]}$, full scale measurement is still the most direct and important way to study the wind pressure distribution of cooling tower $[10,11]$.

An earlier literature report on the field measurement of surface wind pressure of cooling tower was the four-tower combined test of the West Burton power plant in the UK in 1960 [12]. In 1971, Niemann carried out field measurement of the Weisweiler cooling tower in Germany [13]. In 1974, Sollenberger and Scanlan conducted field measurements of Martin's Creek cooling tower in Pennsylvania, USA [14]. Peking University and xi 'an institute of thermal engineering carried out field measurements on two prototype cooling towers(90m height) in Matou, Hebei province(in 1981) and Maoming, Guangdong province(in 1982) and their data has been adopted by Chinese codes ${ }^{\text {[15]. Due }}$ to the limitation of tower height and measuring instruments at that time, dynamic characteristics and surface wind load pulsation characteristics could not be fully considered [16]. In 2015, Chen carried out field measurement of large-scale cooling tower in Xu-zhou, China. The measured results of the prototype large cooling tower are updated [17, 18, 19, 20, 21].

Unfortunately, the measured wind speed of cooling tower was not big before. Under the condition of ultra-high $\mathrm{Re}$, the distribution data of wind pressure (average and extreme) on the surface of cooling tower are lack. And the wind load code has not made clear provisions. Besides, the field test data of ribbed cooling tower is very few.

In order to analyze the distribution law of average and extreme wind pressure on the surface of cooling tower, field measurements were carried out on a ribbed cooling tower.

The cooling tower is a kind of double-curved thin shell structure of cast-in-place reinforced concrete. The tower height is $155 \mathrm{~m}$, the throat height is $116.25 \mathrm{~m}$, and the throat diameter is $68 \mathrm{~m}$. 60 ribs are arranged in equal space on the outer wall of the cooling tower. The tower tube is supported by 40 pairs of rectangular cross section " $X$ " shaped pillars of reinforced concrete (see Figure 1). 


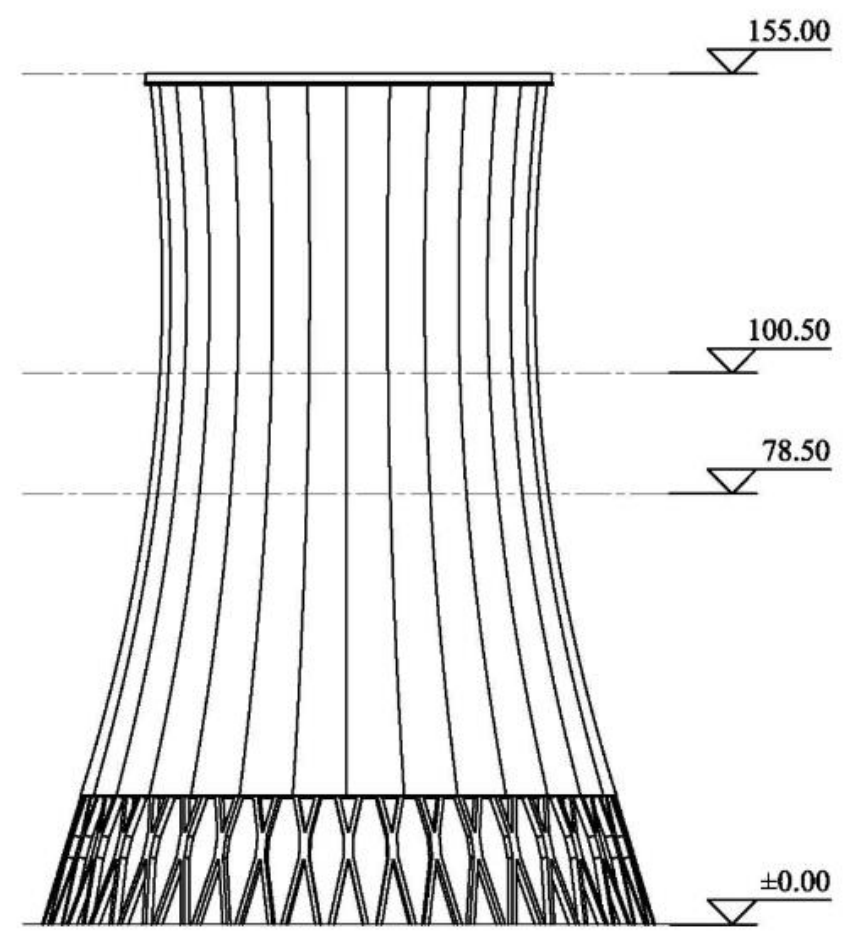

Fig. 1 - Chematic diagram of the cooling tower

The cooling tower is located in Toksun County, Turpan Region, Xinjiang. The site of the cooling tower is flat, with no mountain or obstacle. There is strong wind all year round in Toksun County. The local recorded maximum wind speed was over $40.0 \mathrm{~m} / \mathrm{s}$, and the maximum wind speed we measured was $25.06 \mathrm{~m} / \mathrm{s}$. It is extremely rare for such high wind speeds to be measured at the cooling tower site. Re of the cooling tower throat is up to $1.06^{\star} E 8$.

According to the original data, the distribution curve of wind pressure under the perennial dominant wind direction was gotten. And we compared it with Code for Design of Cooling for Industrial Recirculating Water [22] (GB/T50102-2014) to find out the differences of average wind pressure distribution between two curves. The influence of Re on the average wind pressure, fluctuating wind pressure and wind pressure at the end of the cooling tower was analyzed. And the distribution of extreme values on the cooling tower surface under the condition of ultra-high $R e$ is analyzed. In addition, the validity of the numerical simulation method was verified by the measured data.

Figure 2 illustrates the main research content. 


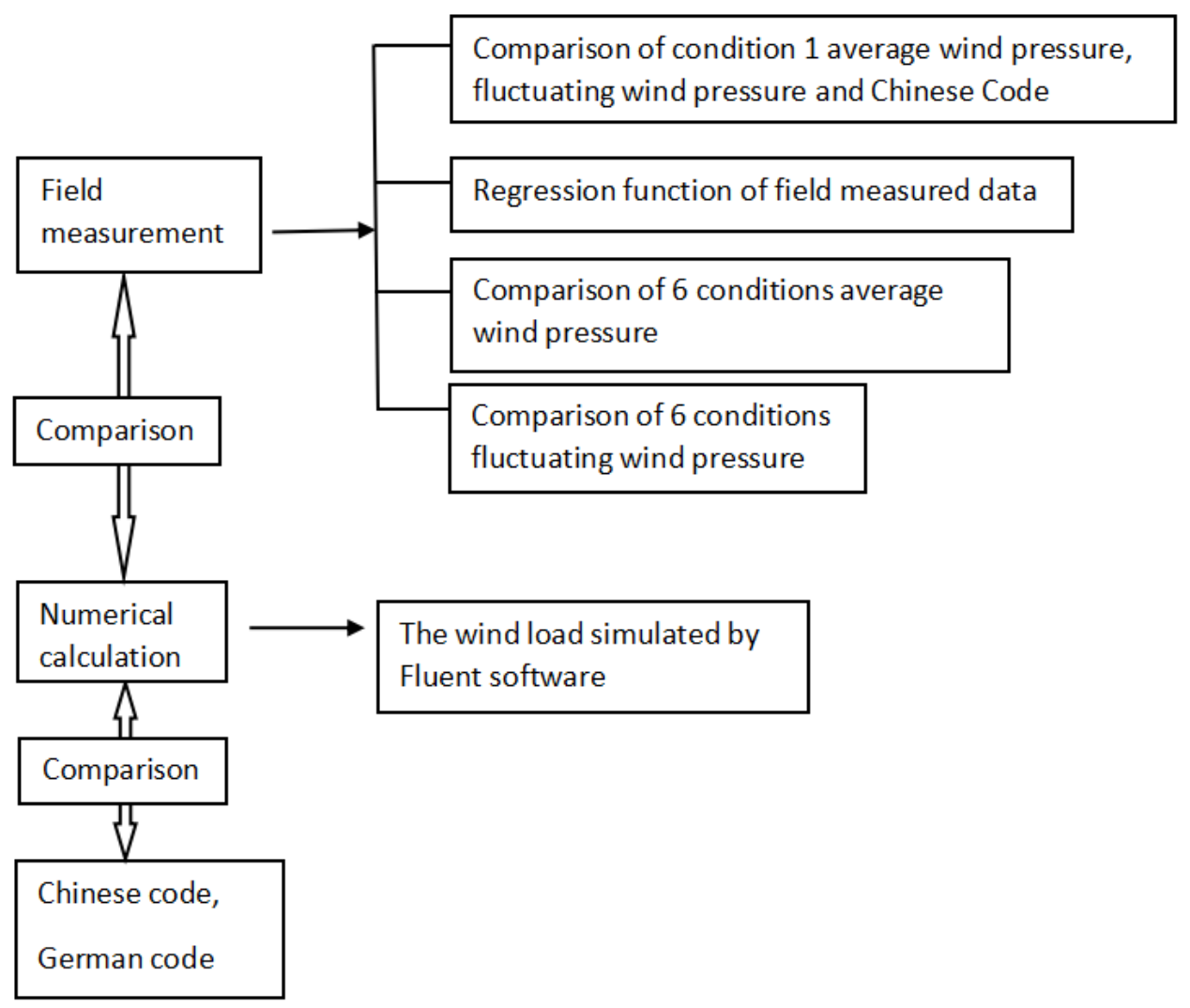

Fig. 2 - General layouts of research works

\section{ANALYSIS OF FIELD MEASUREMENT RESULTS}

Field measurements of wind pressure, wind speed and direction were carried out for two years at intervals of $10-\mathrm{sec}$, and a total of $6,220,800$ sets of data were recorded. The wind pressure monitoring position was selected as 78.5 meters high section. And the 30 measuring points on the cooling tower were arranged in the center of the two ribs and uniformly arranged along the annular direction (see Figure 3).

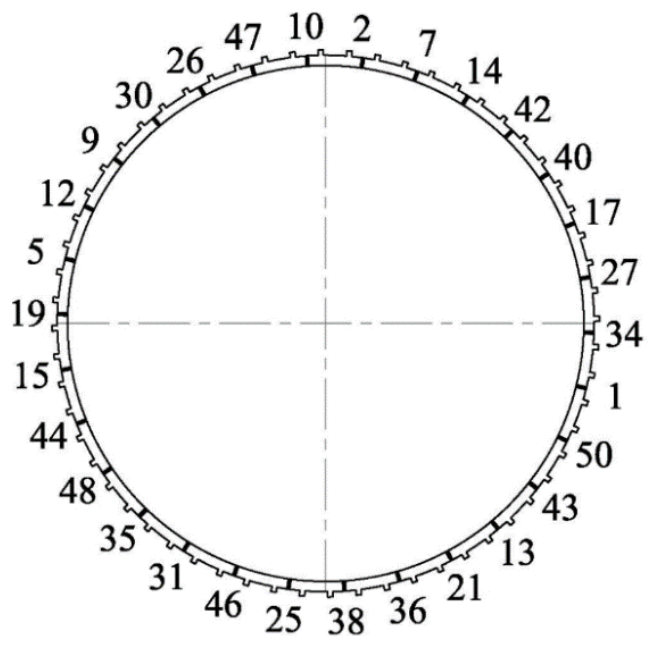


Fig.3 - Layout of measuring points with a height of 78.5 meters

\section{Calculation of wind pressure coefficient}

The ratio of the actual pressure or suction caused by wind on the surface of buildings to the wind pressure of incoming flow is called the wind pressure coefficient [23].

$$
\begin{aligned}
& \text { Average wind pressure } \bar{p}_{i}=\frac{\sum_{j=1}^{N} p_{i j}}{N}, \\
& \qquad \sigma_{p i}=\sqrt{\frac{\sum_{j=1}^{N}\left(p_{i j}-\bar{p}_{i}\right)^{2}}{N-1}}
\end{aligned}
$$

Where, $p_{i j}$ is the pressure value measured at the measuring point $i$ at the moment $\mathrm{j}$, and $\mathrm{N}$ is the total number of measured pressure values.

$$
\text { Average wind pressure coefficient } C_{p i}=\frac{\bar{p}_{i}-p_{\infty}}{0.5 \rho v^{2}}
$$

Where, $p_{\infty}$ is the reference static pressure, and $\rho, \mathrm{V}$ represent air density and incoming wind speed, respectively.

$$
\text { Fluctuating wind pressure coefficient } C_{o p i}=\frac{\sigma_{p i}}{0.5 \rho v^{2}}
$$

Due to the limitations of test conditions and the influence of tower landform and surrounding buildings, it is very difficult to get the accurate incoming wind speed in the wind pressure measurement. Therefore, the average wind pressure and fluctuating wind pressure at each measuring point are obtained by dimensionless normalization of the maximum wind pressure at the tower (i.e., stagnation pressure) in this paper.

Load Code for the Design of Building Structures (GB50009-2012) ${ }^{[23]}$ stipulates that the average wind time interval is $10 \mathrm{~min}$, and the wind pressure data is averaged according to the measured sample data with 10min as the basic time interval. Because of the high wind speed of the northwest wind in history, the northwest wind is chosen as the calculation condition (wind direction of each working condition is relatively stable). Firstly, working condition 1 and working condition 2 are calculated (each working period is $10 \mathrm{~min}$ ). Because the wind speed and pressure data fluctuate greatly within 10min, working conditions 3 to 6 are calculated (all time periods are less than 10min, in order to ensure the wind speed and wind direction are relatively stable). Re (cooling tower throat) is calculated using the average wind speed (cooling tower throat) (see Table 1). 
Article no. 65

THE CIVIL ENGINEERING JOURNAL 4-2021

ENGINEERING

JOURNAL

Tab. 1 - Calculated condition

\begin{tabular}{|c|c|c|c|c|c|}
\hline $\begin{array}{c}\text { Serial } \\
\text { number }\end{array}$ & Time & $\begin{array}{c}\text { Maximum } \\
\text { wind speed } \\
(\mathrm{m} / \mathrm{s})\end{array}$ & $\begin{array}{c}\text { average wind speed }(\mathrm{m} / \mathrm{s}) \\
(15 \text { meters above the } \\
\text { ground) }\end{array}$ & $\begin{array}{c}\text { average wind } \\
\text { speed } \\
(\mathrm{m} / \mathrm{s}) \text { (cooling } \\
\text { tower throat) }\end{array}$ & $\begin{array}{c}\mathrm{Re} \text { (cooling } \\
\text { tower throat) }\end{array}$ \\
\hline 1 & $\begin{array}{c}2016-04-23 \\
18: 43: 03--18: 53: 03\end{array}$ & 14.53 & 8.4 & 11.42 & $46.78^{*} 10^{6}$ \\
\hline 2 & $\begin{array}{c}2016-04-24 \\
14: 30: 03--14: 40: 03\end{array}$ & 25.06 & 12.7 & 17.27 & $70.74^{*} 10^{6}$ \\
\hline 3 & $\begin{array}{c}2016-04-24 \\
14: 30: 42--14: 32: 22\end{array}$ & 23.2 & 16.6 & 22.57 & $92.46^{*} 10^{6}$ \\
\hline 4 & $\begin{array}{c}2016-4-23 \\
18: 36: 13--18: 37: 23\end{array}$ & 12.59 & 9.7 & 13.19 & $54.03^{*} 10^{6}$ \\
\hline 5 & $\begin{array}{c}2016-04-29 \\
20: 12: 03--20: 13: 03\end{array}$ & 13.18 & 11.27 & 15.32 & $62.76^{*} 10^{6}$ \\
\hline 6 & $\begin{array}{c}2016-04-23 \\
20: 29: 24--20: 30: 22\end{array}$ & 8.04 & 6.61 & 8.99 & $36.83^{*} 10^{6}$ \\
\hline
\end{tabular}

\section{Wind pressure distribution of condition 1}

The distribution of average wind pressure coefficient, and fluctuating wind pressure coefficient (measured value of working condition 1) are compared with the distribution of average wind pressure coefficient (ribbed, non-ribbed) in the code (GB/T50102-2014) [22] (see Figure 4).

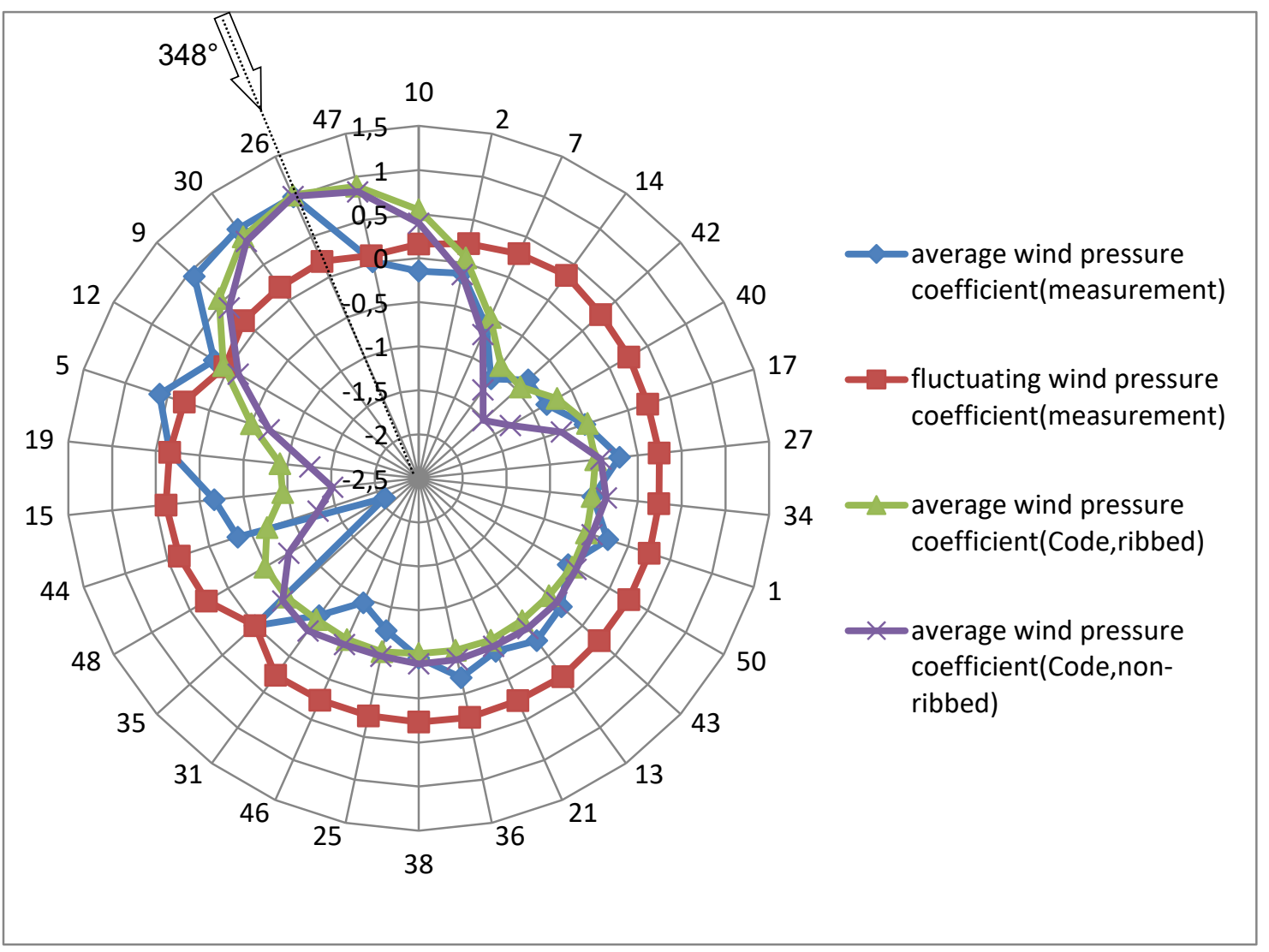


Fig. 4 - Comparison of wind pressure coefficient

Figure 4 shows that the measured average wind pressure on the cooling tower surface in working condition 1 is basically consistent with GB/T50102-2014.

Next, the average wind pressure coefficient of 6 kinds of field measured data in Table 1 is regressed into the form of the code (GB/T50102-2014).

$$
C_{p}(\theta)=\sum_{k=0}^{9} \alpha_{k} \cos k \theta=\alpha_{0}+\alpha_{1} \cos \theta+\alpha_{2} \cos 2 \theta+\cdots+\alpha_{9} \cos 9 \theta
$$

In which,

$\theta=0^{\circ}, 12^{\circ}, 24^{\circ}, 36^{\circ}, 48^{\circ}, 60^{\circ}, 72^{\circ}, 84^{\circ}, 96^{\circ}, 108^{\circ}, 120^{\circ}, 132^{\circ}, 144^{\circ}, 156^{\circ}, 168^{\circ}, 180^{\circ}$ (corresponding to 16 measuring points).

$\theta=0^{\circ}$ is the wind direction corresponding to the maximum average wind pressure in $10 \mathrm{~min}$.

The coefficient of wind pressure distribution curve of ribbed cooling tower obtained by regression of measured data is

$[\alpha]^{\prime}=[-0.5993,0.4784,0.6235,0.3063,-0.0696,-0.0488,0.091,0.0773,0.0601,0.0454]$. While $[\alpha]^{\prime}=[-0.31816,0.42197,0.48519,0.38374,0.13956,-0.05178,-0.07171,0.00106,0.03127,-0.00025]$ in the code (GB/T50102-2014).

\section{Comparison of 6 working conditions}

The distribution of the average wind pressure coefficient measured in the field from working conditions 1 to 6 is compared with that in GB/T50102-2014, regression curve. (see Figure 5).

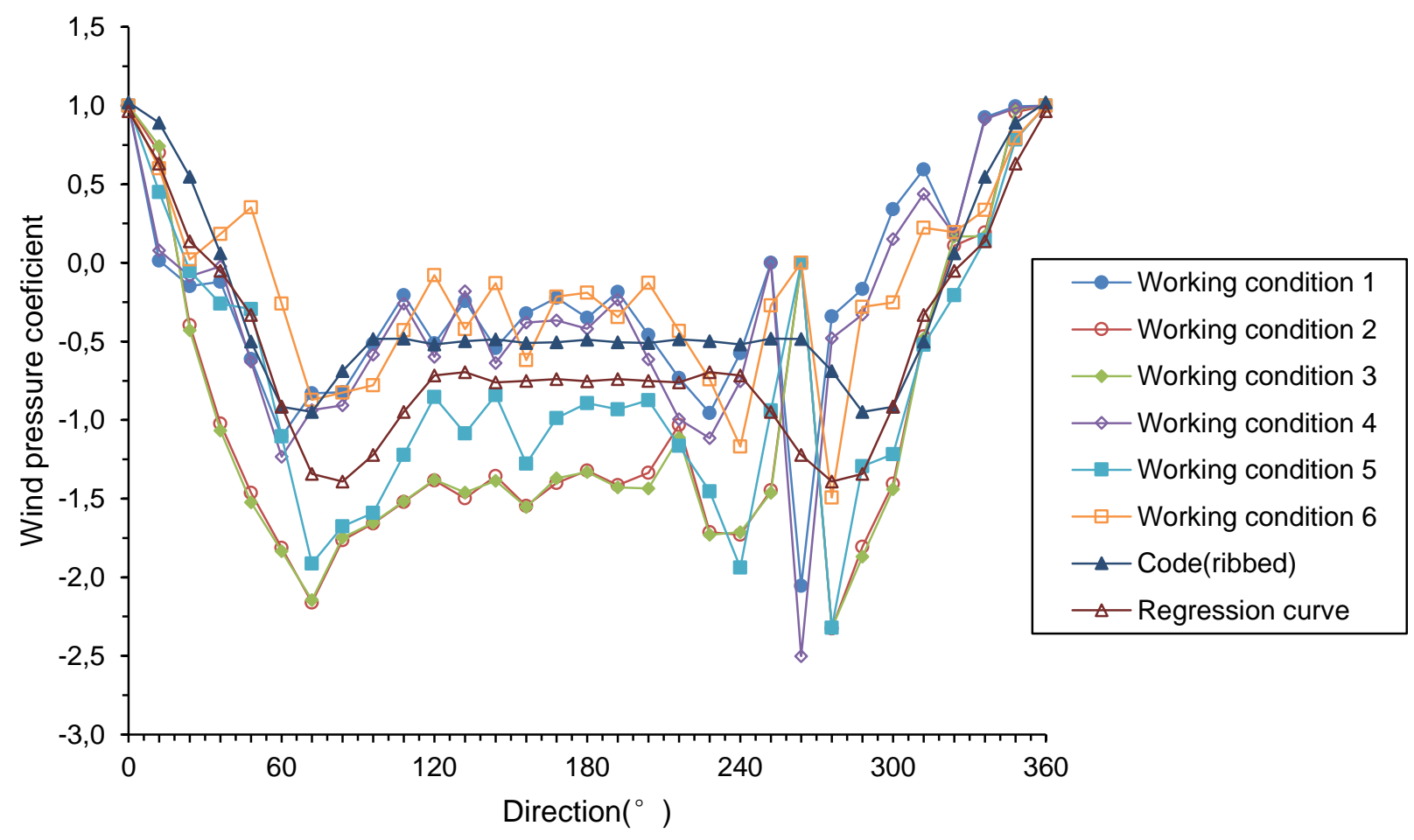

Fig. 5 - Distribution comparison of average wind pressure coefficient 
From Figure 5, average wind pressure coefficients in working conditions 1, 4 and 6(the average wind speed is less than $10 \mathrm{~m} / \mathrm{s}$ ) are close to the code value (GB/T50102-2014), while average wind pressure coefficients in working conditions 2,3,5(the average wind speed is greater than $10 \mathrm{~m} / \mathrm{s}$ ) are far from the code value (GB/T50102-2014). The higher the wind speed is, the higher the surface wind pressure of the cooling tower is. And average wind pressure coefficients in working conditions 2 , 3, 5 are greater than the code value (GB/T50102-2014).

In addition, the distribution law of wind pressure coefficient at the end of cooling tower varies with Re (see Table 2).

Tab. 2: Comparison table of the average wind pressure coefficient of cooling tower tail in the field measurement and in the code (GB/T50102-2014) with Re variation

\begin{tabular}{|c|c|c|c|c|}
\hline $\begin{array}{c}\text { Working } \\
\text { conditions }\end{array}$ & $\begin{array}{c}\text { Average wind } \\
\text { speed (m/s) }\end{array}$ & Re & $\begin{array}{c}\text { Average wind } \\
\text { pressure } \\
\text { coefficient of } \\
\text { cooling tower } \\
\text { tail in the field } \\
\text { measurement }\end{array}$ & $\begin{array}{c}\text { Average wind } \\
\text { pressure } \\
\text { coefficient of } \\
\text { cooling tower } \\
\text { tail in the code }\end{array}$ \\
\hline $\begin{array}{c}\text { Working } \\
\text { Condition 1 }\end{array}$ & 8.4 & $46.78^{*} 10^{6}$ & -0.37 & -0.50 \\
\hline $\begin{array}{c}\text { Working } \\
\text { Condition 2 }\end{array}$ & 12.7 & $70.74^{*} 10^{6}$ & -1.42 & -0.50 \\
\hline $\begin{array}{c}\text { Working } \\
\text { conditions3 }\end{array}$ & 16.6 & $92.46^{*} 10^{6}$ & -1.51 & -0.50 \\
\hline $\begin{array}{c}\text { Working } \\
\text { conditions4 }\end{array}$ & 9.7 & $54.03^{*} 10^{6}$ & -0.39 & -0.50 \\
\hline $\begin{array}{c}\text { Working } \\
\text { conditions5 }\end{array}$ & 11.27 & $62.76^{*} 10^{6}$ & -0.97 & -0.50 \\
\hline $\begin{array}{c}\text { Working } \\
\text { conditions6 }\end{array}$ & 6.61 & $36.83^{*} 10^{6}$ & -0.27 & -0.50 \\
\hline
\end{tabular}

It can be seen from Table 2 that when the wind speed is $9.7 \mathrm{~m} / \mathrm{s}$ (working condition 4 ), the average wind pressure coefficient of cooling tower tail in the field measurement is the closest to that in GB/T50102-2014. The larger the wind speed is (the greater Re is), the larger the absolute value of the average negative pressure of the tail wind pressure coefficient is. This rule should be paid attention to in the design.

The characteristics of the flow field outside the tower are analyzed from the mechanism. In the transcritical region, with the increase of $\mathrm{Re}$, the transition point moves upstream until near the forward standstill point, the separation point moves forward, and the absolute value of minimum pressure coefficient and back pressure coefficient increases.

Comparison diagram of the measured fluctuating wind pressure coefficient distribution under working conditions $1 \sim 6$ is shown in Figure 6. From Figure 6, working conditions 2 and 3 have the maximum average wind speed, and have large fluctuations in fluctuating wind pressure. The lower the wind speed is, the lower the fluctuating wind pressure is. 

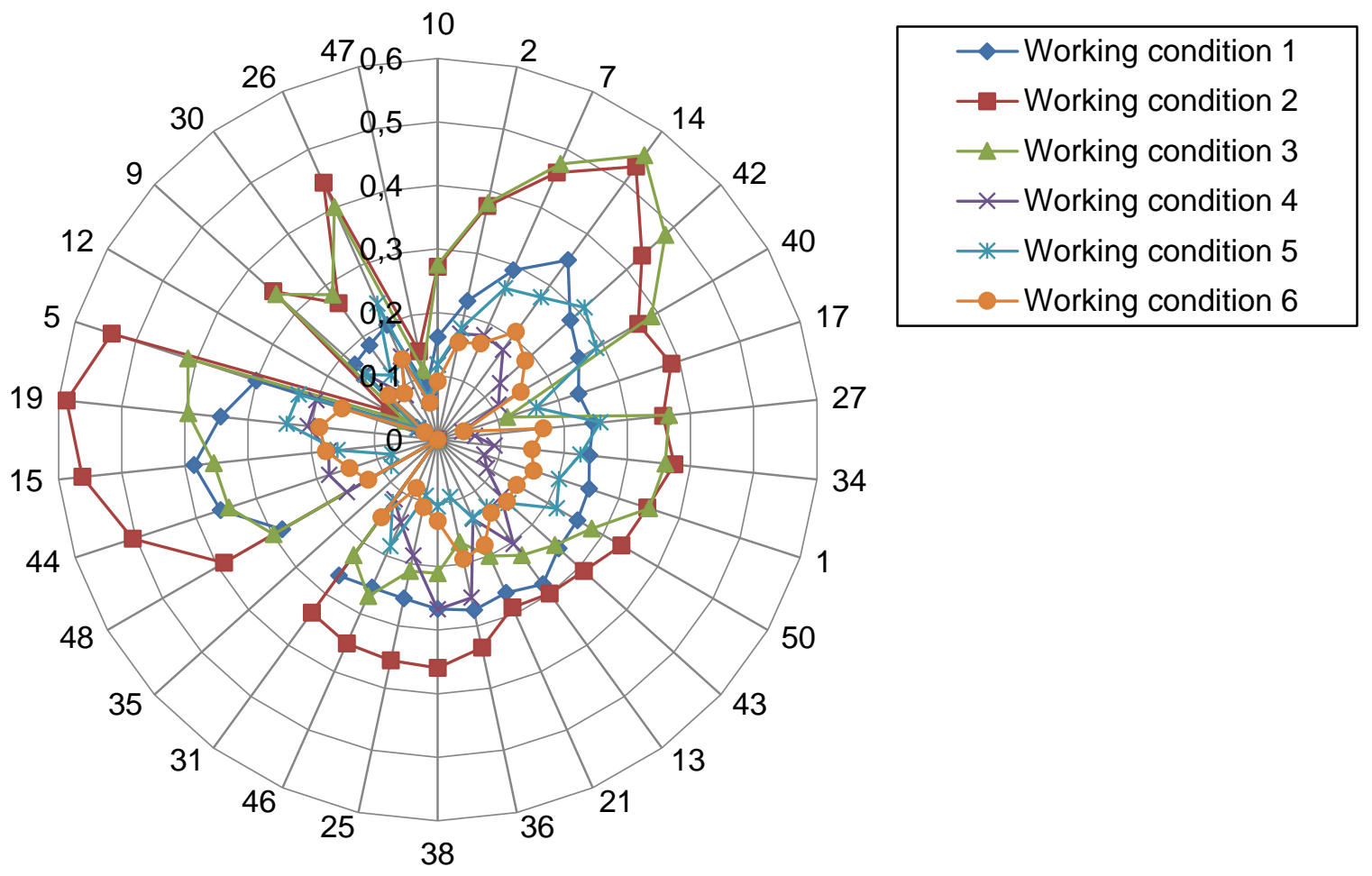

Fig.6 - Comparison diagram of fluctuating wind pressure coefficient

\section{NUMERICAL CALCULATION}

Because there are few field measured data, it is necessary to compare it with numerical simula tion calculation to gather experience for wind pressure simulation calculation of cooling tower.

\section{The numerical modeling}

The numerical analysis does not consider the deformation of the cooling tower under the action of wind load. The physical model adopted by the calculation is shown in Figure 1. In the rectangular region adopted in this paper, the boundary of the windward face is $5 \mathrm{H}$ away from the model center $(\mathrm{H}$ is the height of the cooling tower), and its left and right boundary and upper boundary are also $5 \mathrm{H}$ away from the model center. In order to better simulate the development of the model's wake, the boundary of its downstream outlet is $10 \mathrm{H}$ away from the model center. The total number of cooling tower grid units is 2.2 million.

The boundary condition of numerical analysis is:

1) The velocity inlet boundary condition on the windward surface of the region is given, and the wind profile of the atmospheric boundary layer is simulated by exponential law.

The section function of turbulence kinetic energy $\mathrm{k}$ and turbulence dissipation ratio is:

$$
\begin{aligned}
k(z) & =1.5 u^{2}(z) I_{u}^{2}(z) \\
\varepsilon(z) & =C_{u}^{3 / 4} k(z)^{3 / 2} / l
\end{aligned}
$$


Where $\mathrm{Cu}=0.09, \mathrm{I}$ is the integral scale of turbulence, and the value here is 0.07 times the building characteristic scale.

UDF function is used to custom entry wind function.

2) Outflow boundary condition is used in export.

3) Symmetric boundary conditions are applied to the top and both sides of the computational domain. The symmetric boundary conditions are equivalent to the wall surface of free slip, and the normal velocity on the boundary is 0 .

4) Non-slip wall conditions are adopted on the surface and ground of the building.

The realizable k-epsilon turbulence model is used. The inlet turbulence intensity is $I_{u}$ $(z)=0.1\left(z / z_{G}\right)^{-\alpha-0.05}$. speed.

B-type geomorphic conditions are adopted, and $u_{10}=18 \mathrm{~m} / \mathrm{s}$ is taken as the reference wind

SIMPLE algorithm is adopted in pressure velocity coupling. And the first order discrete scheme is adopted in the momentum equation, the turbulent kinetic energy equation and the dissipation rate equation of the turbulent kinetic energy.

The criterion for calculating iterative convergence is that the residual of all variables drops below $10^{-5}$ and the variation of parameters in the flow field tends to be steady. The non-equilibrium wall function method is used to deal with the turbulence near the wall.

\section{Comparison among numerical simulation, field measurement results and Code}

The wind load can be simulated by Fluent software. And the average wind pressure coefficients measured in the field are compared with that in the Chinese code (GB/T50102-2014) [22], in the German code (VGB-R 610Ue, 2005) [24] (6 VGB curves are given according to the surface roughness from the German Code) and in numerical simulation (see Figure 7).

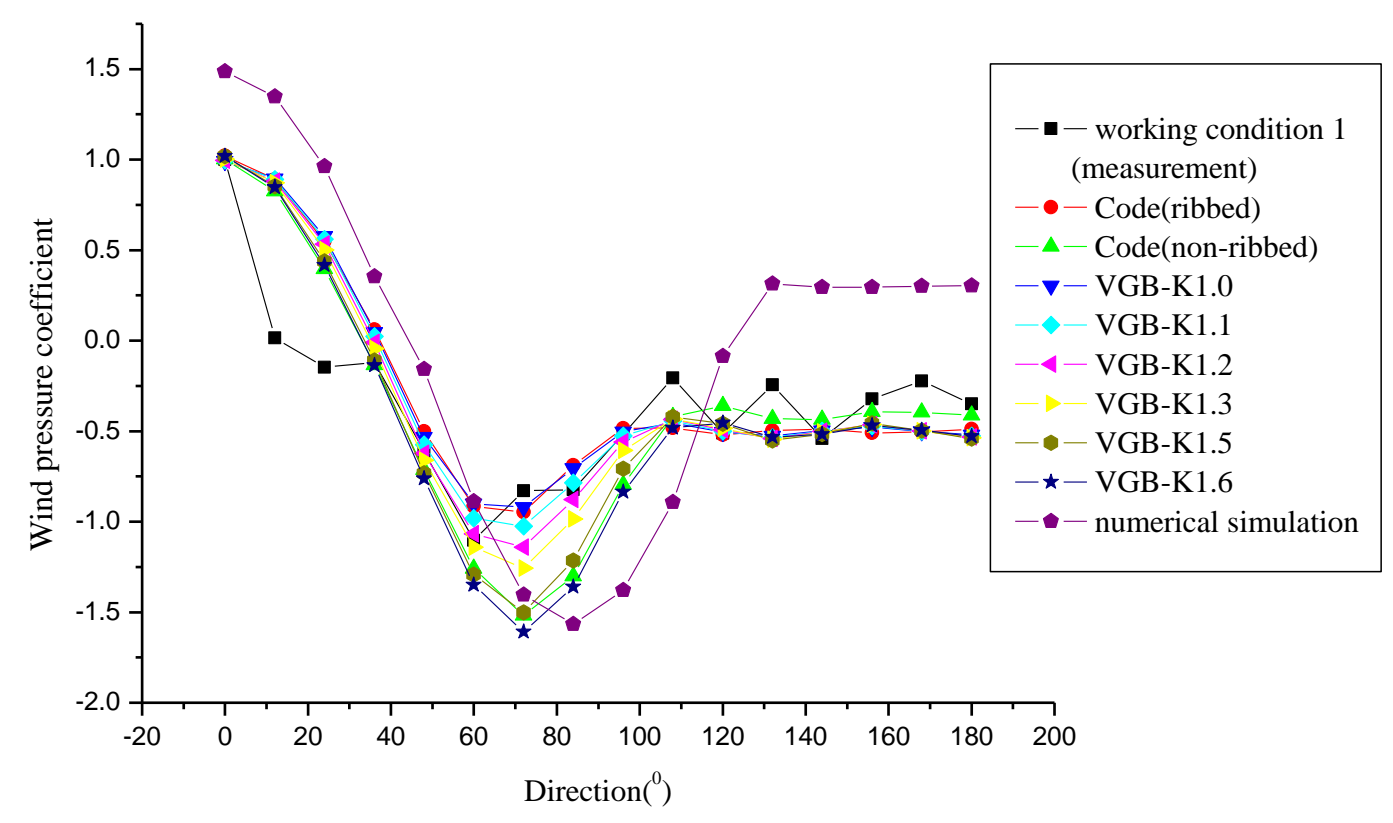


Fig. 7 - The comparison diagram of the average wind pressure coefficient between the numerical calculation and the field measurement, the Chinese code and the German code

From Figure 7, the variation law of the numerical simulation results is consistent with that in the field measurement and the code.

\section{CONCLUSIONS}

In this paper, the wind pressure of the ribbed cooling tower has been measured on site, and the wind load of the cooling tower has been calculated by Fluent. The conclusions of this study are as follows:

(1) The maximum wind speed reached $25.06 \mathrm{~m} / \mathrm{s}$ during the field measurement, and the corresponding wind pressure data is very valuable.

(2) When the wind speed is $9.7 \mathrm{~m} / \mathrm{s}$ (working condition 4), the average wind pressure coefficient of cooling tower tail in the field measurement is the closest to that in the code (GB/T50102-2014).

When the average wind speed is greater than $10 \mathrm{~m} / \mathrm{s}$, the absolute value of the negative pressure at the end of the cooling tower is greater than the absolute value of the code (GB/T501022014). The greater the wind speed is, the greater the absolute value of the negative pressure is at the end of the cooling tower. This rule should be paid attention to in the design.

(3) The higher the average wind speed is, the greater the pressure pulsation is.

(4) The variation law of numerical simulation result is consistent with that of the field measurement and the code. This indicates that the numerical simulation can be used to qualitatively analyze the wind pressure of the cooling tower.

\section{DATA AVAILABILITY:}

The data in this paper are reliable and can be used.

\section{ACKNOWLEDGEMENTS}

This research was supported by National Science Foundation of China (11502177), Key Laboratory of Concrete and Pre-stressed Concrete Structure of Ministry of Education (Southeast University) Project (CPCSME2019-08), the Opening Foundation of Hubei Key Laboratory of digital textile equipment (DTL2019019), Wuhan Textile University Project

(201608006,201703002,2016JXTD06,2017XNFZ02).

The authors declare no conflict of interest.

\section{REFRENCES}

[1] Zhao, Lin, Yaojun Ge, and Ahsan Kareem, 2017. Fluctuating Wind Pressure Distribution Around FullScale Cooling Towers. Journal of Wind Engineering and Industrial Aerodynamics 165 : 34-45. doi:10.1016/j.jweia.02.016.

[2] Sun, T.F., Z.F. Gu, L.M. Zhou, P.H. Li, and G.L. Cai, 1992.Full-Scale Measurement and Wind-Tunnel Testing of Wind Loading on Two Neighboring Cooling Towers. Journal of Wind Engineering and Industrial Aerodynamics 43, no. 1-3: 2213-2224. doi:10.1016/0167-6105(92)90660-3. 
[3] KAREEM, A., and C.M. CHENG, 1999.Pressure and Force Fluctuations on Isolated Roughened Circular Cylinders of Finite Height in Boundary Layer Flows. Journal of Fluids and Structures 13, no. 7-8: 907-933. doi:10.1006/jfls.1999.0247.

[4] Cheng, X.X., L. Zhao, Y.J. Ge, J. Dong, and C. Demartino, 2017.A Comprehensive High Reynolds Number Effects Simulation Method for Wind Pressures on Cooling Tower Models. Wind and Structures 24, no. 2: 119-144. doi:10.12989/was.2017.24.2.119.

[5] Orlando, Maurizio, 2001.Wind-Induced Interference Effects on Two Adjacent Cooling Towers. Engineering Structures 23, no. 8: 979-992. doi:10.1016/s0141-0296(00)00110-3.

[6] Noh, Hyuk Chun, 2006.Nonlinear Behavior and Ultimate Load Bearing Capacity of Reinforced Concrete Natural Draught Cooling Tower Shell. Engineering Structures 28, no. 3: 399-410. doi:10.1016/j.engstruct.2005.08.016.

[7] Ke, Shitang, and Yaojun Ge, 2015.Extreme Wind Pressures and Non-Gaussian Characteristics for Super-Large Hyperbolic Cooling Towers Considering Aeroelastic Effect. Journal of Engineering Mechanics 141, no. 7: 04015010. doi:10.1061/(asce)em.1943-7889.0000922.

[8] Zahlten, Wolfhard, and Claudio Borri, 1998. Time-domain simulation of the non-linear response of cooling tower shells subjected to stochastic wind loading. Engineering structures 10.20:881-889.

[9] Zou, Yun-feng, Xu-hui He, Hai-quan Jing, Shuai Zhou, Hua-wei Niu, and Zheng-qing Chen,2018. Characteristics of Wind-Induced Displacement of Super-Large Cooling Tower Based-on Continuous Medium Model Wind Tunnel Test. Journal of Wind Engineering and Industrial Aerodynamics 180: 201-212. doi:10.1016/j.jweia.2018.08.001.

[10] Ke, Shitang, Hao Wang, and Yaojun Ge, 2019. Comparison of Stationary and Non-Stationary WindInduced Responses of a Super-Large Cooling Tower Based on Field Measurements. Thin-Walled Structures 137: 331-346. doi:10.1016/j.tws.2019.01.017.

[11] Wang, H., S.T. Ke, and Y.J. Ge, 2019. Research on Non-Stationary Wind-Induced Effects and the Working Mechanism of Full Scale Super-Large Cooling Tower Based on Field Measurement. Journal of Wind Engineering and Industrial Aerodynamics 184: 61-76. doi:10.1016/j.jweia.2018.11.015.

[12] Armitt J, 1980.Wind loading on cooling towers. Journal of Structural Division.

[13] Niemann, H.-J., and H. Pröpper, 1975.Some Properties of Fluctuating Wind Pressures on a Full-Scale Cooling Tower. Journal of Wind Engineering and Industrial Aerodynamics 1: 349-359. doi:10.1016/01676105(75)90029-x.

[14] Sollenberger N J, Scanlan R H, 1974.Pressure-difference measurements across the shell of a full-scale natural draft cooling tower. Proceedings of the symposium on fullscale measurements of wind effects (Canada: University of Western Ontario).

[15] Sun Tianfeng, 1983. Full-size measurement and wind tunnel research on wind pressure distribution of non-ribbed hyperbolic cooling towers. Acta Aerodynamica Sinica 4.

[16] Wang, Hao, Shitang Ke, Yaojun Ge, and Yukio Tamura, 2018. Extreme and Spectrum Characteristics of Wind Loads on Super-Large Cooling Tower Under Different Four-Tower Combinations. Advances in Structural Engineering 22, no. 5: 1238-1250. doi:10.1177/1369433218810888.

[17] Cheng, XX, L Zhao, YJ Ge, R Dong, and C Demartino, 2016. Wind Effects on Rough-Walled and Smooth-Walled Large Cooling Towers. Advances in Structural Engineering 20, no. 6: 843-864. doi:10.1177/1369433216664354.

[18] Cheng, XX, J Dong, Y Peng, L Zhao, and YJ Ge, 2017.Effects of Free-Stream Turbulence on Wind Loads on a Full-Scale Large Cooling Tower. Advances in Structural Engineering 21, no. 10 : 1437-1453. doi:10.1177/1369433217747404.

[19] Cheng, X.X., S.T. Ke, P.F. Li, Y.J. Ge, and L. Zhao,2019.External Extreme Wind Pressure Distribution for the Structural Design of Cooling Towers. Engineering Structures 181: 336-353. doi:10.1016/j.engstruct.2018.12.038. 
[20] Cheng, XX, G Wu, L Zhao, PF Li, and YJ Ge, 2019.Wind-Induced Internal Pressures on Large Cooling Towers. Advances in Structural Engineering 22, no. 15: 3249-3261. doi:10.1177/1369433219861727.

[21] Cheng, X.X., L. Zhao, Y.J. Ge, S.T. Ke, and X.P. Liu, 2015. Wind Pressures on a Large Cooling Tower. Advances in Structural Engineering 18, no. 2: 201-219. doi:10.1260/1369-4332.18.2.201.

[22] Ministry of Construction of PRC.GB/T50102-2014, 2014.Code for Design of Cooling for Industrial Recirculating Water. (Beijing: China Electric Power Press).

[23] Ministry of Construction of PRC.GB50009-2012, 2012. Load Code for the Design of Building Structures. (Beijing: China Architecture \&Building Press).

[24] VGB-R 610Ue, 2005.Structural design of cooling towers. 